\title{
A VMI Model in Supplier-Driven Supply Chain and Its Performance Simulation
}

\author{
Qiuzheng $\mathrm{Li}^{1,2}$ \\ ${ }^{1}$ School of Economics, Nankai University, Tianjin, China \\ ${ }^{2}$ School of Logistics Management, Zhejiang Wanli University, Ningbo, China \\ liqiuzheng@sina.com
}

\begin{abstract}
This research builds a VMI inventory decision model of supplier-driver supply chain to analyze the effects of VMI on a supply chain performance and announce the important function of VMI in promoting supply chain coordination, reducing costs and increasing profits. According to this model, VMI is found always to reduce the system's(buyer and supplier together) and the buyer's inventory related costs in the short-term, but the supplier's inventory related costs varies. Under certain cost conditions between buyer and supplier, VMI can increase the system's and the buyer's profits. And the supplier's profits can be increased under other conditions. Using the corresponding MATLAB program, obtains some calculation results. And through computer simulation, analyzes the effects of VMI on supply chain performance, and announces the important function of VMI in promoting supply chain coordination, reducing costs and increasing profits.
\end{abstract}

Index Terms-VMI, supply chain, inventory management, profits, costs

\section{INTRODUCTION}

VMI (vendor-managed inventory, called VMI) is a win-win cooperation strategy for buyers and suppliers, in which the supply chain inventory is managed by the supplier according to a common agreement[1]. As a new inventory management thinking, VMI can enhance the coordination of the supply chain and improve supply chain performance[2]. It is not a fashion, but an important supply chain strategy [3]. However, some companies are not quite sure of the potential benefits of the VMI system. Therefore, systematic evaluating VMI's supply chain performance and the effects on the parties will be helpful to establish a coordinated supply chain relationships.

The present researches on VMI mainly focus on application area, lacking of depth study on the supply chain performance of VMI. Yan Dong and Kefeng Xu (2002) established a VMI supply chain model based on the buyer-driven supply chain relationship including single-supplier and single-buyer. This research evaluated how VMI affects a supply channel. Specifically, VMI always leads to a higher buyer's profits, but supplier's profits varies. In the short-term, VMI is found to reduce total costs of the channel system, but under certain cost conditions between buyer and supplier, it could decrease the purchasing price and supplier's profits. In the longrun, it could more likely increase supplier's profits than in the short-run[4]. Based on this model, Hong Zhu et al (2004) further considered the occasions with initial inventory and short of inventory, proved that VMI can reduce the total supply chain costs in the short-term, but the inventory costs of suppliers are increased[5]. Hai-feng Guo et al (2005) proved that in the long-term, the optimal supply chain purchase quantity with VMI is higher than traditional supply chain, and the buyer's profits will increase. In match conditions, or long-term incentive, the supplier's profits will also increase[6]. Using the VMI supply chain model, they further proved that the channel profits with VMI is more than the traditional supply chain in short-term incentive, and in the long-term VMI can do better in increasing channel profits than in the shortterm[7].

The above literatures are quite helpful to the quantitative analysis of VMI's supply chain performance. But these researches only considered the case of buyerdriven supply chain, without discussing the situations of supplier-driven. As the inventory decision-making process is different in the two types of supply chain, it should be discussed separately. This paper will research the VMI decision model and its supply chain performance in the supplier-driven supply chain, in order to more fully reflect the value of VMI.

\section{RESEARCH ASSUMPTIONS AND SYMBOLS DEFINITION}

\section{Research assumptions}

In order to facilitate the analysis, we choose a singleproduct supply chain with a supplier and a buyer as the research object. And the buyer's sales quantity is the same as the purchases quantity. Assumptions: (1) Market demand is deterministic, known, and is a function of selling price; (2) Lead time is known and deterministic; (3) Batch replenishment, and one-time arrival; (4) No stock-outs; (5) The buyer's replenishment quantity is the same as the supplier's production quantity; (6) The decision objective is to maximize profits. In reality, because of strength difference, both enterprises in the supply chain have different decision-making positions (mainly reflected in the product's pricing). Thus, it appears two kinds of supply chain (i.e. buyer-driven supply chain and supplier-driven supply chain). 
In the case of supplier-driven supply chain, the purchase price is determined by the supplier. The buyer will only be able to accept this price and determine the purchase quantity and sale price, according to its cost characteristics, so as to make its own profits maximization. Then the supplier tries to make its own profits maximization by adjusting the purchase price, according to the purchase quantity that the buyer can accomplish under a specific purchase price. This paper will select the supplier-driven supply chain to study.

\section{Symbols definition}

$R_{B}$-The buyer's annual profits; $d$ - The buyer's annual demand, that is, annual sales or purchases; $p(d)$ The buyer's selling price function, the function of the inverse function of demand, with sales $d$ increases; $w$ Contract purchase price determined by the supplier; $\mathrm{O}_{B}{ }^{-}$ The buyer's ordering cost per purchasing; $H_{B}$ - The buyer's inventory holding cost per unit of product; $Q_{B}$ Purchase quantity determined by the buyer; $R_{S}$ - The supplier's annual profits; $C(d)$ - Production and distribution cost function of the supplier; $\mathrm{O}_{S}$ - Sum of production costs and order processing costs per batch of the supplier; $H_{S}$ - The supplier's inventory holding cost per unit of product; $R_{B}^{v}$ - The buyer's annual profits with VMI; $d_{v}$ - The buyer's annual demand with VMI; $p\left(d_{v}\right)$ - The buyer's selling price function with VMI; $w_{v}$-Contract purchase price determined by the supplier with VMI; $I_{v}$ - Total inventory related costs of the supply chain with VMI; $I_{B}^{v}$-The buyer's inventory related costs with VMI; $I_{S}^{v}$-The supplier's inventory related costs with VMI.

\section{MODEL STRUCTURE}

\section{Model Structure before VMI}

Before application of VMI, the supplier produces in accordance with the buyer's order quantity. Thus, both of them hold inventory and have inventory related costs. The buyer's profits function is given as follows:

$$
R_{B}=p(d) \cdot d-w \cdot d-\left(\frac{d}{Q_{B}} O_{B}+\frac{Q_{B}}{2} H_{B}\right)
$$

And the supplier's profits function is:

$$
R_{S}=w \cdot d-C(d)-\left(\frac{d}{Q_{S}} O_{S}+\frac{Q_{S}}{2} H_{S}\right)
$$

In this decision-making process, the buyer first determines the optimal purchase quantity. According to assumptions, by using the economic order quantity(EOQ) calculation model, we can know the buyer's optimal purchase quantity is:

$$
Q_{B}^{*}=E O Q_{B}=\sqrt{\frac{2 O_{B} \cdot d}{H_{B}}}
$$

The buyer's inventory related cost (i.e. the sum of ordering cost and inventory holding cost) is:

$$
I_{B}=\sqrt{2 H_{B} \cdot O_{B} \cdot d}
$$

Therefore, the profits function of the buyer in the optimal order strategy becomes:

$$
R_{B}=p(d) \cdot d-w \cdot d-\sqrt{2 H_{B} \cdot O_{B} \cdot d}
$$

And the profits function of the supplier becomes:

$$
R_{S}=w \cdot d-C(d)-\left(O_{S} \sqrt{\frac{d \cdot H_{B}}{2 O_{B}}}+H_{S} \sqrt{\frac{d \cdot O_{B}}{2 H_{B}}}\right)
$$

For any given purchase price $w$ from the supplier, the buyer chooses a selling price $p(d)$ so as to determine the sales quantity $d$ to maximize its own profits. It can be obtained from the first-order condition:

$$
w=p^{\prime}(d) \cdot d+p(d)-\sqrt{\frac{H_{B} \cdot O_{B}}{2 d}}
$$

Realizing this relationship between the buyer's final sales and the purchase price, the supplier then maximizes its profits by adjusting price to affect the purchasing quantity $d$. The optimal quantity $d^{*}$ can be obtained from the first-order condition of (6) by incorporating (7):

$p^{\prime \prime}\left(d^{*}\right) \cdot d^{* 2}+3 p^{\prime}\left(d^{*}\right) \cdot d^{*}+p\left(d^{*}\right)-C\left(d^{*}\right)-\frac{1}{2}\left(1+\frac{O_{S}}{O_{B}}+\frac{H_{S}}{H_{B}}\right) \sqrt{\frac{O_{B} \cdot H_{B}}{2 d^{*}}}=0$

$d^{*}$ exists when the second-condition is satisfied, then the optimal purchase price $w^{*}$ and the optimal selling price $p^{*}$ can be calculated out based on $d^{*}$.

\section{Model Structure under VMI}

Now the two parties decide to adopt a VMI system, the buyer's inventory will be managed by the supplier, and the supplier will determine the inventory levels, order quantities, lead time, etc., the buyer will no longer manage its inventory system.

The buyer's profits function under VMI becomes:

$$
R_{B}^{v}=p\left(d_{v}\right) \cdot d_{v}-w_{v} \cdot d_{v}
$$

And the supplier's profits function under VMI becomes:

$$
R_{S}^{v}=w_{v} \cdot d_{v}-C\left(d_{v}\right)-\left[\frac{d_{v}}{Q_{v}}\left(O_{S}+O_{B}\right)+\frac{Q_{v}}{2}\left(H_{S}+H_{B}\right)\right]
$$

Under the economic order quantity,

$$
R_{S}^{v}=w_{v} \cdot d_{v}-C\left(d_{v}\right)-\sqrt{2\left(O_{S}+O_{B}\right) \cdot\left(H_{S}+H_{B}\right) \cdot d_{v}}
$$

Since the buyer's inventory is managed by the supplier, inventory related cost is no longer included in the buyer's profits function, and the supplier's order cost 
becomes $\left(\mathrm{O}_{S}+\mathrm{O}_{B}\right)$, inventory holding cost becomes $\left(H_{S}+H_{B}\right)$. Similarly, we can get the relationship function between the purchase price and the buyer's selling quantity under VMI from the first-order condition:

$$
w_{v}=p^{\prime}\left(d_{v}\right) \cdot d_{v}+p\left(d_{v}\right)
$$

Again, the optimal quantity $d_{v}^{*}$ can be obtained from the first-order condition of (11) by incorporating (12):

$p^{\prime \prime}\left(d_{v}^{*}\right) \cdot d_{v}^{* 2}+3 p^{\prime}\left(d_{v}^{*}\right) \cdot d_{v}^{*}+p\left(d_{v}^{*}\right)-C\left(d_{v}^{*}\right)-\sqrt{\frac{\left(O_{S}+O_{B}\right) \cdot\left(H_{S}+H_{B}\right)}{2 d_{v}^{*}}}=0$

$d_{v}^{*}$ exists when the second-order condition is satisfied, then the optimal purchase price $w_{v}^{*}$ and the optimal selling price $p_{v}^{*}$ can be calculated out based on $d_{v}^{*}$.

\section{EFFECT OF VMI ON INVENTORY RELATED COSTS}

The short-term effect of VMI is often the important reason for the parties to decide whether to continue applying VMI. In the early stages of VMI application, due to market constraints, agreements with other parties or balanced relationship, the sales and purchases are stable, that is, to maintain the level before the application of VMI, and the same to the selling price. In the short term, the effect of VMI is mainly reflected in the inventory-related costs.

\section{Effect of VMI on the system inventory-related costs}

The system inventory-related costs before application of VMI are:

$I=I_{B}+I_{S}=\sqrt{2 H_{B} \cdot O_{B} \cdot d}+\left(O_{S} \sqrt{\frac{d \cdot H_{B}}{2 O_{B}}}+H_{S} \sqrt{\frac{d \cdot O_{B}}{2 H_{B}}}\right)$

And the system inventory-related costs after application of VMI are:

$$
I_{v}=I_{B}^{v}+I_{S}^{v}=\sqrt{2\left(O_{S}+O_{B}\right) \cdot\left(H_{S}+H_{B}\right) \cdot d_{v}}
$$

Since

$$
I-I_{v}=\sqrt{\frac{d \cdot H_{B} \cdot O_{B}}{2}} \cdot\left(\sqrt{1+\frac{O_{S}}{O_{B}}}-\sqrt{1+\frac{H_{S}}{H_{B}}}\right)^{2} \geq 0
$$

So long as $\frac{O_{S}}{O_{B}} \neq \frac{H_{S}}{H_{B}}$, the system inventory-related costs can be reduced by VMI system.

\section{Effect of VMI on the supplier's inventory-related costs}

Although the buyer can achieve zero-inventory through VMI, the supplier's inventory related cost is possible to rise.

Since

$$
\begin{aligned}
I_{S}-I_{S}^{v} & =\sqrt{\frac{d \cdot H_{B} \cdot O_{B}}{2}} \cdot\left[\left(\sqrt{1+\frac{O_{S}}{O_{B}}}-\sqrt{1+\frac{H_{S}}{H_{B}}}\right)^{2}-2\right] \\
I_{S} & -I_{S}^{v} \geq 0
\end{aligned}
$$

only when $\left|\sqrt{1+\frac{O_{S}}{O_{B}}}-\sqrt{1+\frac{H_{S}}{H_{B}}}\right| \geq \sqrt{2}$.

In this occasion, the supplier's inventory-related cost will be reduced.

Conclusion 1: In the case of supplier-driven supply chain, VMI can reduce the system's(buyer and supplier together) and the buyer's inventory related costs in the short-term, but the supplier's inventory related costs can be reduced if and only if

$$
\left|\sqrt{1+\frac{O_{S}}{O_{B}}}-\sqrt{1+\frac{H_{S}}{H_{B}}}\right| \geq \sqrt{2} .
$$

\section{EFFECT OF VMI ON THE PROFITS OF THE SUPPLY CHAIN}

We can evaluate this effect by comparing the profits level before and after VMI under the optimal order quantity.

\section{Effect of VMI on the system profits of the supply chain}

From (9) and (11), we know that:

$$
R_{B}^{v}+R_{S}^{v}=p\left(d_{v}\right) \cdot d_{v}-C\left(d_{v}\right)-\sqrt{2\left(O_{S}+O_{B}\right) \cdot\left(H_{S}+H_{B}\right) \cdot d_{v}}
$$

From the first-order condition of $\left(R_{B}^{v}+R_{S}^{v}\right)$ at the point of $d_{v}=d_{v}^{*}$, we can obtain:

$$
\left.\frac{\partial\left(R_{\mathrm{B}}^{v}+R_{S}^{v}\right)}{\partial\left(d_{v}\right)}\right|_{d_{v}=d_{v}^{*}}=p\left(d_{v}^{*}\right)+p^{\prime}\left(d_{v}^{*}\right) d_{v}^{*}-C\left(d_{v}^{*}\right)-\sqrt{\frac{\left(O_{S}+O_{B}\right) \cdot\left(H_{S}+H_{B}\right)}{2 d_{v}^{*}}}
$$

Subtracting the right of (13) from the left of (19), and the result is not less than zero when the first-order condition and second-order condition of the price function are not positive. That is,

$-p^{\prime \prime}\left(d_{v}^{*}\right) d_{v}^{* 2}-2 p^{\prime}\left(d_{v}^{*}\right) d_{v}^{*} \geq 0$

And $d_{v}^{*}$ is in the increasing interval of the function $\left(R_{B}^{v}+R_{S}^{v}\right)$.

From (5) and (6),

$R=R_{B}+R_{S}=p(d) d-c(d)-\sqrt{2 O_{B} \cdot H_{B} \cdot d}-\left(O_{S} \sqrt{\frac{d \cdot H_{B}}{2 O_{B}}}+H_{S} \sqrt{\frac{d \cdot O_{B}}{2 H_{B}}}\right)$

Since

$R_{v}\left(d^{*}\right)-R\left(d^{*}\right)=\sqrt{\frac{d \cdot H_{B} \cdot O_{B}}{2}} \cdot\left(\sqrt{1+\frac{O_{S}}{O_{B}}}-\sqrt{1+\frac{H_{S}}{H_{B}}}\right)^{2} \geq 0$

$$
R_{v}\left(d_{v}^{*}\right) \geq R\left(d^{*}\right) \quad \text { when } \quad d_{v}^{*} \geq d^{*}
$$
$\left.\left|\sqrt{1+\frac{O_{S}}{O_{B}}}-\sqrt{1+\frac{H_{S}}{H_{B}}}\right| \geq 1\right)$. But this is not critical condition. In addition, when the second-order condition of the price function is greater than zero, the discussion needs to do another. 
Effect of VMI on the profits of the buyer

From the first-order condition of $R_{B}^{v}$ at the point of $d_{v}=d_{v}^{*}$, we can obtain,

$$
\left.\frac{\partial R_{B}^{v}}{\partial d_{v}}\right|_{d_{v}=d_{v}^{*}}=p\left(d_{v}^{*}\right)+p^{\prime}\left(d_{v}^{*}\right) d_{v}^{*}-w_{v}
$$

Subtracting the right of (13) from the left of the (23), and the result is not less than zero when the first-order condition and second-order condition of the price function are not positive. That is,

$$
-p^{\prime \prime}\left(d_{v}^{*}\right) d_{v}^{* 2}-2 p^{\prime}\left(d_{v}^{*}\right) d_{v}^{*}+C\left(d_{v}^{*}\right)+\sqrt{\frac{\left(O_{S}+O_{B}\right) \cdot\left(H_{S}+H_{B}\right)}{2 d_{v}^{*}}} \geq 0
$$

And $d_{v}^{*}$ is in the increasing interval of $R_{B}^{v}$.

Since

$$
R_{B}^{v}\left(d^{*}\right)-R_{B}\left(d^{*}\right)=\sqrt{2 O_{B} \cdot H_{B} \cdot d^{*}}>0
$$

When

$$
\begin{aligned}
& d_{v}^{*} \geq d^{*}\left(\text { i.e., }\left|\sqrt{1+\frac{O_{S}}{O_{B}}}-\sqrt{1+\frac{H_{S}}{H_{B}}}\right| \geq 1\right), \\
& R_{B}^{v}\left(d_{v}^{*}\right)-R_{B}\left(d^{*}\right) \geq R_{B}^{v}\left(d^{*}\right)-R_{B}\left(d^{*}\right)=\sqrt{2 O_{B} \cdot H_{B} \cdot d^{*}}>0
\end{aligned}
$$

That is, $R_{B}^{v}\left(d_{v}^{*}\right)>R_{B}\left(d^{*}\right)$. But this is not critical condition. In addition, when the second-order condition of the price function is greater than zero, the discussion needs to do another.

Effect of VMI on the profits of the supplier.

$d_{v}^{*}$ is the maximum point of the supplier's profits after application of VMI, thus,

$R_{S}^{\prime}\left(d_{v}^{*}\right)-R_{S}\left(d^{*}\right) \geq R_{S}^{y}\left(d^{*}\right)-R_{S}\left(d^{*}\right)=\sqrt{\frac{d \cdot H_{B} \cdot O_{B}}{2}} \cdot\left[\left(\sqrt{1+\frac{O_{S}}{O_{B}}}-\sqrt{1+\frac{H_{S}}{H_{B}}}\right)^{2}-2\right]$

And $R_{S}^{v}\left(d_{v}^{*}\right) \geq R_{S}\left(d^{*}\right)$ when $\left|\sqrt{1+\frac{O_{S}}{O_{B}}}-\sqrt{1+\frac{H_{S}}{H_{B}}}\right| \geq \sqrt{2}$.

Conclusion 2: In the case of supplier-driven supply chain, VMI can increase the system's and the buyer's profits when $d_{v}^{*} \geq d^{*}$ (i.e., $\left|\sqrt{1+\frac{O_{S}}{O_{B}}}-\sqrt{1+\frac{H_{S}}{H_{B}}}\right| \geq 1$ ). And when $\left|\sqrt{1+\frac{O_{S}}{O_{B}}}-\sqrt{1+\frac{H_{S}}{H_{B}}}\right| \geq \sqrt{2}$ (Non-stringent threshold condition), the supplier's profits can be increased.

VI. EFFECT OF VMI ON THE TOTAL ANNUAL PURCHASE AMOUNT OF THE SUPPLY CHAIN

From (8) and (13), we know that:

$$
\begin{aligned}
& p^{\prime \prime}(d) \cdot d^{2}+3 p^{\prime}(d) \cdot d+p(d)-C(d)-\sqrt{\frac{\left(O_{S}+O_{B}\right) \cdot\left(H_{S}+H_{B}\right)}{2 d}} \\
& -\left[p^{\prime \prime}(d) \cdot d^{2}+3 p^{\prime}(d) \cdot d+p(d)-C(d)-\frac{1}{2}\left(1+\frac{O_{S}}{O_{B}}+\frac{H_{S}}{H_{B}}\right) \sqrt{\frac{O_{B} \cdot H_{B}}{2 d}}\right] \\
& =\frac{1}{2}\left(1+\frac{O_{S}}{O_{B}}+\frac{H_{S}}{H_{B}}\right) \sqrt{\frac{O_{B} \cdot H_{B}}{2 d}}-\sqrt{\frac{\left(O_{S}+O_{B}\right) \cdot\left(H_{S}+H_{B}\right)}{2 d}} \\
& =\frac{1}{2} \sqrt{\frac{O_{B} \cdot H_{B}}{2 d}} \cdot\left[\left(\sqrt{1+\frac{O_{S}}{O_{B}}}-\sqrt{1+\frac{H_{S}}{H_{B}}}\right)^{2}-1\right]
\end{aligned}
$$

Therefore, when $\left|\sqrt{1+\frac{O_{S}}{O_{B}}}-\sqrt{1+\frac{H_{S}}{H_{B}}}\right| \geq 1$, type (28) is not less than zero. And if (8) is satisfied,

$$
\begin{aligned}
& p^{\prime}\left(d^{*}\right) \cdot d^{* 2}+3 p^{\prime}\left(d^{*}\right) \cdot d^{*}+p\left(d^{*}\right)-C\left(d^{*}\right)-\sqrt{\frac{\left(O_{S}+O_{B}\right) \cdot\left(H_{S}+H_{B}\right)}{2 d^{*}}} \\
& \geq p^{\prime \prime}\left(d^{*}\right) \cdot d^{* 2}+3 p^{\prime}\left(d^{*}\right) \cdot d^{*}+p\left(d^{*}\right)-C\left(d^{*}\right)-\frac{1}{2}\left(1+\frac{O_{S}}{O_{B}}+\frac{H_{S}}{H_{B}}\right) \sqrt{\frac{O_{B} \cdot H_{B}}{2 d^{*}}}=0
\end{aligned}
$$

Since the first-order condition of the profit function is a decreasing function, in case of $\left|\sqrt{1+\frac{O_{S}}{O_{B}}}-\sqrt{1+\frac{H_{S}}{H_{B}}}\right| \geq 1$, $d_{v}^{*} \geq d^{*}$, and on the contrary, $d_{v}^{*}<d^{*}$.

Conclusion 3: When $\left|\sqrt{1+\frac{O_{S}}{O_{B}}}-\sqrt{1+\frac{H_{S}}{H_{B}}}\right| \geq 1$, the implementation of VMI can increase the total annual purchase amount of the supply chain.

\section{EFFECT OF VMI ON THE PURCHASE PRICE OF THE SUPPLY CHAIN}

From (7) and (12), we know that the difference between the purchase price before and after application of VMI is:

$w_{v}-w=p^{\prime}\left(d_{v}\right) \cdot d_{v}+p\left(d_{v}\right)-p^{\prime}(d) \cdot d-p(d)+\sqrt{\frac{H_{B} \cdot O_{B}}{2 d}}$

When $d_{v}=d, w_{v}-w=\sqrt{\frac{H_{B} \cdot O_{B}}{2 d}}>0$.

Conclusion 3: In the short term $\left(d_{v}=d\right)$, VMI can increase the purchase price. But in the long term $\left(d_{v} \neq d\right.$ ), it depends on the relationships between $d_{v}$ and $d$, as well as the features of function $p(d)$. 


\section{CALCULATION CASE}

\section{Calculation case}

We assume the price function is $p(d)=a-b \cdot d,(a, b>0)$, and the supplier's cost function is $C(d)=\delta \cdot d+0.5 \theta \cdot d^{2},(\delta, \theta>0)$. Please note that $C^{\prime}(d), C^{\prime \prime}(d)>0, p^{\prime}(d)<0$. This case is cited from [4] based on the relationship of VMI between a telecom equipment manufacturer (as supplier) and its customer. In this case, the manufacturer's order cost is $O_{S}=1500$ (USD) and inventory holding cost is $H_{S}=9$ (USD / year - unit). The buyer's ordering cost is $O_{B}=300$ (USD) and inventory holding cost is $H_{B}=9$ (USD / year $\bullet$ unit). ${ }^{[4]}$ (The parameters values see Table I ).

TABLE I. PARAMETERS SHEET OF THE SPECIFIC CASE

\begin{tabular}{l|c|c|c|c|c|c|c|c}
\hline Parameters & $a$ & $b$ & $\delta$ & $\theta$ & $O_{S}$ & $O_{B}$ & $H_{S}$ & $H_{B}$ \\
\hline Value & 80 & 0.01 & 40 & 0.005 & 1500 & 300 & 9 & 9 \\
\hline
\end{tabular}

We can obtain the results using the established model and the corresponding MATLAB program (see Table II).

TABLE II. THE RESULTS OF THE SPECIFIC CASE

\begin{tabular}{c|c|c|c|c|c|c|c|c|c}
\hline $\begin{array}{c}\text { VMI } \\
\text { or not }\end{array}$ & $d$ & $p$ & $w$ & $I_{B}$ & $I_{S}$ & $I_{T}$ & $R_{B}$ & $R_{S}$ & $R_{T}$ \\
\hline $\mathrm{N}$ & 787.0 & 72.1 & 63.0 & 2061.5 & 6184.5 & 8246.0 & 5162.9 & 11723.0 & 16885.0 \\
\hline $\mathrm{Y}$ & 788.1 & 72.1 & 64.2 & 0 & 7146.2 & 7146.2 & 7225.9 & 11800.0 & 19026.0 \\
\hline
\end{tabular}

From the data of Table II, we know that in the supplier-driven supply chain, the total system profits are increased and the total inventory-related costs are decreased significantly under VMI.

\section{Simulation}

The VMI's effects on supply chain performance contact closely to the cost structure between the two parties (i.e., the relationship between $\frac{H_{S}}{H_{B}}$ and $\frac{O_{S}}{O_{B}}$ ). Furthermore, the cost structure is one of the factors most likely to change in supply chain. In order to test the foregoing conclusions and search for the trend of VMI effects on supply chain performance with the variation of supply chain cost structure, we will do some simulation analysis for the costs, profits and other indicators. The following variations of $O_{S}$ will be representative of the cost structure changes (the increase of $\mathrm{O}_{S}$ on behalf of the increase of stock structural differences between the two parties). (Results shown in Table III).

TABLE III. CALCULATION SHEET OF SUPPLIER-DRIVEN SUPPLY CHAIN

\begin{tabular}{|c|c|c|c|c|c|c|c|c|c|c|}
\hline$O_{S}$ & $\begin{array}{c}\text { VMI } \\
\text { Or } \\
\text { not }\end{array}$ & $d$ & $p$ & $w$ & $I_{B}$ & $I_{S}$ & $I_{T}$ & $R_{B}$ & $R_{S}$ & $R_{T}$ \\
\hline \multirow{2}{*}{0} & $\mathrm{~N}$ & 861.1 & 71.4 & 61.5 & 2156.4 & 1078.2 & 3234.6 & 6336.7 & 17272.0 & $\begin{array}{c}23609 . \\
0\end{array}$ \\
\hline & $\mathrm{Y}$ & 849.3 & 71.5 & 63.0 & 0 & 3028.6 & 3028.6 & 8477.0 & 16337.0 & $\begin{array}{c}24814 . \\
0\end{array}$ \\
\hline \multirow{2}{*}{300} & $\mathrm{~N}$ & 846.8 & 71.5 & 61.8 & 2138.4 & 2138.4 & 4276.8 & 6101.5 & 16144.0 & $\begin{array}{c}22245 . \\
0\end{array}$ \\
\hline & $\mathrm{Y}$ & 832.3 & 71.7 & 63.4 & 0 & 4240.0 & 4240.0 & 8219.5 & 15024.0 & $\begin{array}{c}23244 . \\
0\end{array}$ \\
\hline \multirow{2}{*}{900} & $\mathrm{~N}$ & 817.5 & 71.8 & 62.4 & 2101.1 & 4202.1 & 6303.2 & 5632.5 & 13914.0 & $\begin{array}{c}19547 . \\
0\end{array}$ \\
\hline & $\mathrm{Y}$ & 807.6 & 71.9 & 63.8 & 0 & 5906.6 & 5906.6 & 7719.9 & 13190.0 & $\begin{array}{c}20910 . \\
0\end{array}$ \\
\hline \multirow{2}{*}{1500} & $\mathbf{N}$ & 787.0 & 72.1 & 63.0 & 2061.5 & 6184.5 & 8246.0 & 5162.9 & 11723.0 & $\begin{array}{c}16885 . \\
0\end{array}$ \\
\hline & $\mathbf{Y}$ & 788.1 & 72.1 & 64.2 & 0 & 7146.2 & 7146.2 & 7225.9 & 11800.0 & $\begin{array}{c}19026 . \\
0\end{array}$ \\
\hline \multirow{2}{*}{2100} & $\mathrm{~N}$ & 755.2 & 72.4 & 63.6 & 2019.4 & 8077.7 & 10097.0 & 4693.6 & 9571.5 & $\begin{array}{c}14265 . \\
0 \\
\end{array}$ \\
\hline & $\mathrm{Y}$ & 771.3 & 72.3 & 64.6 & 0 & 8163.4 & 8163.4 & 6731.9 & 10642.0 & $\begin{array}{c}17374 . \\
0\end{array}$ \\
\hline \multirow{2}{*}{2700} & $\mathrm{~N}$ & 721.7 & 72.8 & 64.2 & $\mid 1974.1$ & 9870.6 & 11845.0 & 4221.4 & 7463.1 & $\begin{array}{c}11685 . \\
0\end{array}$ \\
\hline & $\mathrm{Y}$ & 756.1 & 72.4 & 64.9 & 0 & 9036.5 & 9036.5 & 6230.8 & 9630.8 & $\begin{array}{c}15862 . \\
0\end{array}$ \\
\hline
\end{tabular}

1) The variation of inventory-related costs under different cost structure.
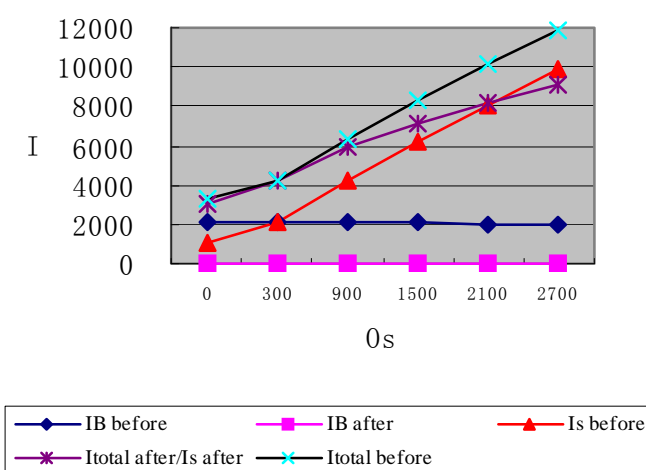

Figure 1. The variation of inventory-related costs under different cost structure 


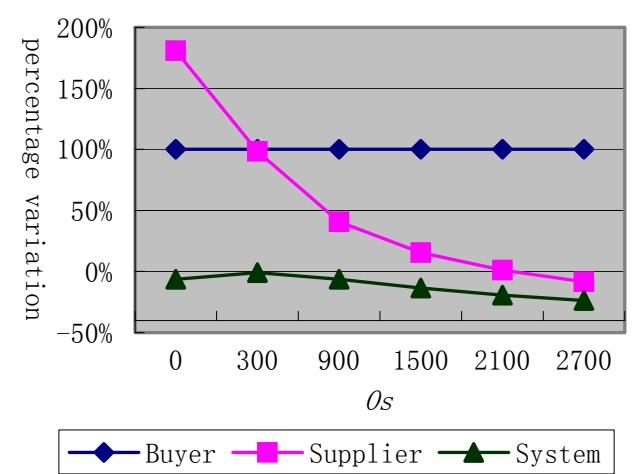

Figure 2. The percentage variation of inventory-related costs under different cost structure

Fig. 1 and Fig. 2 show that with increasing of $O_{S}$, the system inventory-related costs and the supplier's have gradually increased, the buyer's inventory-related costs decreased slightly before VMI and reduced to zero after VMI. Under different cost structures, the buyer's and the system's inventory-related costs are reduced before and after the application of VMI, but the supplier's inventoryrelated costs may be increased or reduced. From the percentage variation, we can see that with increasing of the cost structure difference, the supplier's inventoryrelated costs increase slowed down and the variation percentage changes from positive to negative. The variation percentage of the system inventory-related costs is always in negative territory, and its trend line is an increased to decreased curve. And the variation percentage of the buyer's inventory costs is always $100 \%$.

2) The variation of profits under different cost structure.

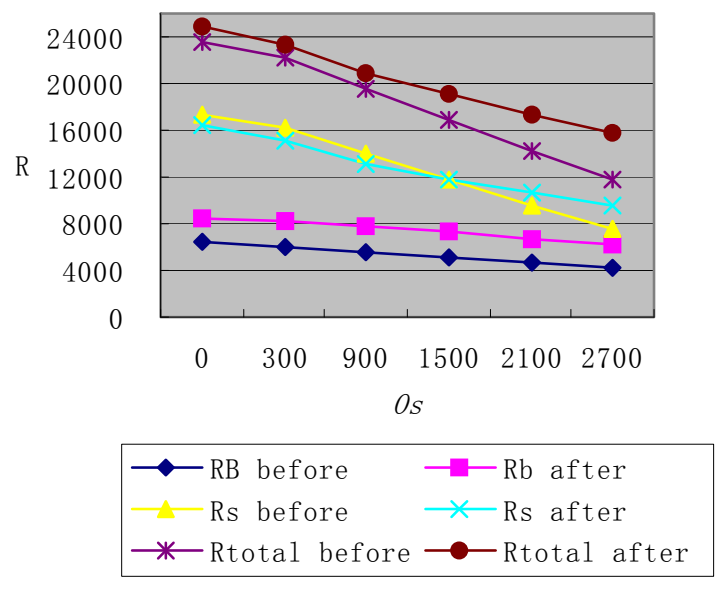

Figure 3. The variation of profits under different cost structure

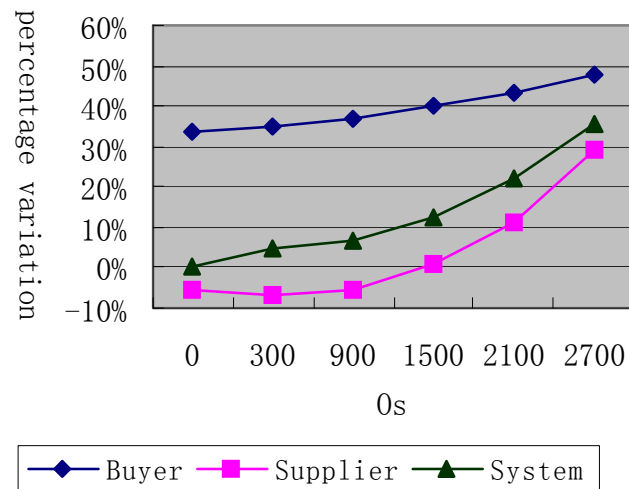

Figure 4. The percentage variation of profits under different cost structure

Fig. 3 and Fig. 4 show that, with increasing of $O_{S}$, the profits of both parties trend to be reduced. Under different cost structure, the system's and the buyer's profits are always increased after the application of VMI, but the supplier's profits may be increased or reduced. From the variation percentage of the profits, we can see that with increasing of the cost structure difference, the increased percentage of the buyer's and the system's profits gradually increase. The variation percentage of the supplier's profits change gradually from negative to positive after the application of VMI, and its trend line is a first slightly reduced and then increased curve.

3) The variation of perchase amount under different cost structure.

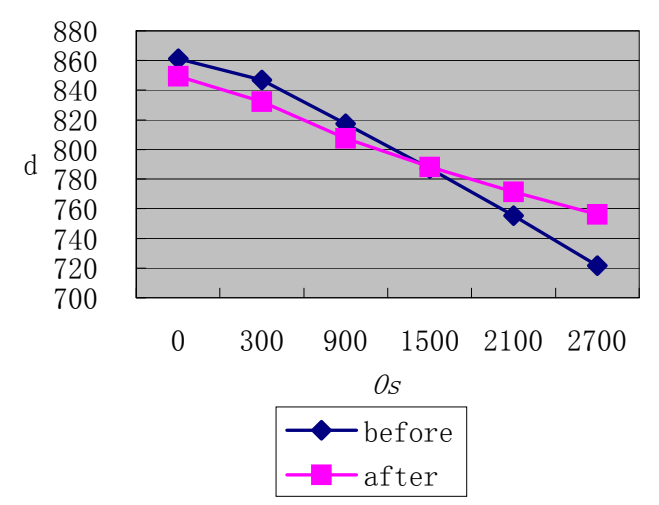

Figure5. The variation of purchase amount under different cost structure 


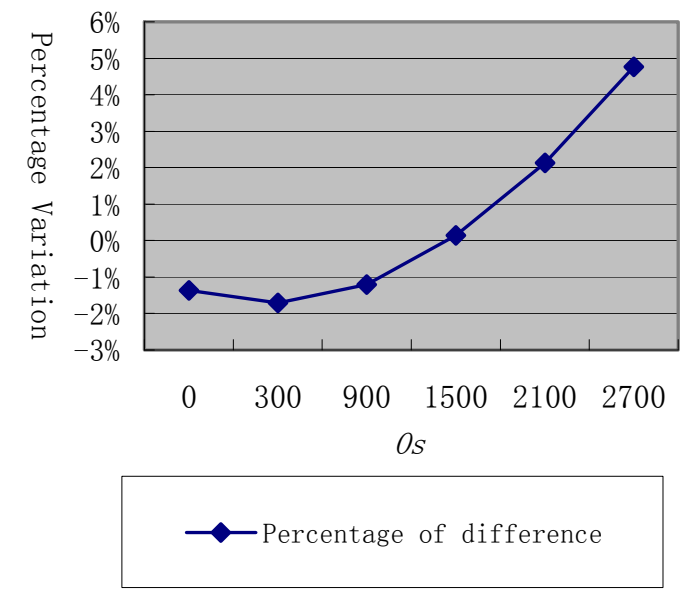

Figure6. The percentage variation of purchase amount under different cost structure

Fig. 5 and Fig. 4 show that, with increasing of $O_{S}$, both of the purchase amounts before and after VMI trend to be reduced. That is due to increasing of contract purchase price $w$ along with costs rising, which caused a chain reaction between buyer and supplier, as a result of the eventually the annual demand reduction. Under different cost structure, the purchase amount may be increased or reduced after the application of VMI. From the variation percentage of the purchase amount, we can see that with increasing of the cost structure difference, the changes of purchase amount turn from negative to positive, and the percentage variation shows a slightly decreasing trend when $O_{S}$ is very small, then it trends evidently to increase.

\section{CONCLUSION AND FUTURE RESEARCH}

This study has evaluated how VMI improve supply chain coordination in a supplier-driven supply chain, and found some important critical condition. But this research on the VMI supply chain model still has some limitations, such as it only considered a single supplier and single retailer supply chain under certain demand, and did not find the strict critical conditions of the VMI impact on supply chain profits. Future research should include the following aspects: VMI inventory model in a singlesupplier and multi-retailer's supply chain, under uncertain demand, in occasion of balanced supply chain; And joint research on VMI's effect on supply chain "synergies" and "reducing the information distortion function".

\section{ACKNOWLEDGMENT}

This research is supported by Science and Technology Plan of Ningbo under Grant No. 2010A10013.

\section{REFERENCES}

[1] Shihua Ma. "Stock is no longer pain - VMI how to reorganize the supply chain inventory management” . China Business, 2001, (22) :39-42.

[2] S.M.Disney, D.R.Towill. The effect of Vendor Managed Inventory (VMI) Dynamics on the Bullwhip Effect in Supply Chains.Int.J.Production Economics,2003,(85):199215.

[3] Andrew B..Vendor-managed Inventory: Fashion Fad or Important Supply Chain Strategy?. Supply Chain Management,1998,(3):10-11.

[4] Yan Dong, Kefeng Xu. A Supply Chain Model of Vendor Managed Inventory. Transportation Research Part E, 2002,(38):75-95

[5] Hong Zhu, Haifeng Guo, Xiaoyuan Huan. VMI's profit model and optimization strategy. Journal of Northeastern University (Natural Science), 2004, (25) :505-507.

[6] Haifeng Guo, Xiaoyuan Huang, Ruozhen Qiu. VMI's optimal purchase quantity and profit. Journal of Northeastern University (Natural Science), 2005, (26) :186-189.

[7] Haifeng Guo, Yunlong Zhu. VMI's channel profit optimization analysis. Operations Research and Management, 2007, (16) :10-14.

Qiuzheng Li was birthed in Hengshui City, Hebei Province, China. Studied in Northeastern University from September 1997 to March 2004 for the Master's degree in field supply chain management, and from September 2006 till now, studied in Nankai University majored in Economics for doctor's degree.

He worked as Manager of logistics department of Shenyang Dawncom Group CO., LTD from February to October, 2001. And served for Zhejiang Wanli University as a Teacher from March 2004 till now. Logistics and supply chain management is his current research interests. 